\title{
Roosevelt e Rondon desvendam um rio amazônico
}

\author{
Roosevelt and Rondon unveil a river in the Amazon \\ JoséAugusto Drummond \\ Professor do Centro de Desenvolvimento Sustentável/Universidade de Brasília. \\ jaldrummond@uol.com.br \\ SQN 206, Bloco J, Ap 102 \\ 70844-000 - Brasília - DF - Brasil
}

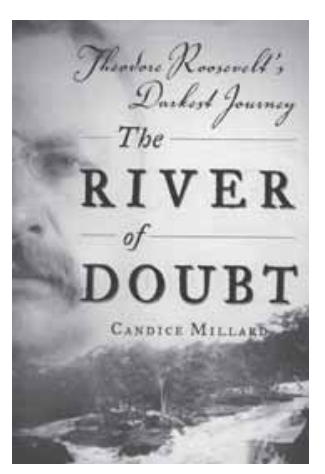

MILLARD, Candice. River of Doubt: Theodore Roosevelt's darkest journey. New York: Doubleday, 2005. 416p.

\begin{abstract}
A jornalista e escritora norte-americana Candice Millard trabaIhou como redatora e editora da National Geographic, influente revista de circulação internacional. Produziu para esse livro um texto denso, solidamente documentado, bem organizado e bem escrito, situado na confluência da biografia com o relato histórico. É fácil de ler e difícil de largar - ele convida a uma leitura rápida e completa. ${ }^{1}$

O texto tem dois ingredientes principais: a detal hada reconstituição de uma famosa e quase trágica expedição pelo coração da Amazônia, combinada com uma interpretação biográfica e psicológica do icônico político norte-americano Theodore Roosevelt (1858-1919). ${ }^{2}$ O primeiro ingrediente, o mais atraente para o leitor brasileiro, relata o que transcorreu entre 1913 e 1914, e ganhou o nome informal de Expedição Roosevelt-Rondon (às vezes chamada Expedição Rondon-Roosevelt), pois a sua liderança foi compartilhada entre Roosevelt e Cândido Mariano da Silva Rondon (1865-1958).
\end{abstract}

Rondon, então coronel do Exército brasileiro, estava no auge de suas atividades e da fama como explorador de vastos e pouco conhecidos trechos dos sertões do Centro-Oeste e da Amazônia, nos quais instalava longas linhas telegráficas que faziam parte de um projeto de integração desses territórios ao Brasil. Em suas andanças levava também cientistas e técnicos, que faziam levantamentos topográficos, geográficos, geológicos, florísticos e faunísticos. Outras expedições demarcavam fronteiras internacionais. Rondon ficou conhecido ainda por fazer contato sistemático com povos nativos pouco conhecidos da sociedade nacional. É notável como Millard, uma escritora estrangeira, aborda de maneira atenta e respeitosa a figura de Rondon, um personagem apenas secundário na sua narrativa ${ }^{3}$, em contraste com o esquecimento ou o tratamento trivial que muitos autores brasileiros dão a esse grande brasileiro. ${ }^{4}$

Para interpretar a biografia política de Roosevelt, o segundo ingrediente do texto, a autora parte do seguinte ponto: quando da sua expedição no Brasil, era político de grande renome, mas que acabara de sofrer sério abalo. Uma estrepitosa derrota eleitoral abriu, na sua carreira, uma crise da qual ele nunca se recuperou. Deputado estadual e governador de Nova York, em 1898, quando era ministro da Marinha, largou o cargo de forma teatral para organizar uma bem divulgada força voluntária (Rough Riders) que participou da 
guerra dos EUA contra os espanhóis, em Cuba, ao lado das Forças Armadas norteamericanas. Essa iniciativa 'patriótica' ajudou-o a ampliar sua fama e a alcançar o posto de presidente dos EUA, exercido entre 1901 e 1909.

Nesse posto capitaneou uma era em que os EUA trocaram o relativo isolacionismo no panorama internacional por uma agressiva política intervencionista em países mais próximos, como Cuba, República Dominicana e Colômbia. Em relação à Colômbia, a administração de Roosevelt esteve por trás da separação de uma área do país que, em 1904, se tornou o Panamá. Nesse país foi construído um canal de navegação de grande interesse para os EUA. No panorama doméstico, a presidência de Roosevelt implantou agressivas políticas desenvolvimentistas, que a literatura chama de progressistas. Em alguns casos, elas confrontaram grandes monopólios estabelecidos em certos setores da economia dos EUA. Entre outros aspectos, isso se expressou na criação de florestas nacionais e reservas minerais (para racionalizar e democratizar o acesso aos recursos naturais) e de parques nacionais e outros tipos de áreas naturais protegidas.

Um importante detalhe biográfico, muito bem explorado por Millard, é que Roosevelt, desde jovem, cultivava a fama de ser um homem rústico (rugged). Gostava de atividades ao ar livre (outdoors), como caçadas, pescarias, acampamentos em locais ermos, expedições terrestres pelos EUA e África. Sobre esses feitos ele mesmo escrevia e publicava relatos que vendiam bem e lhe rendiam frutos políticos, pois ajudavam a construir junto aos norteamericanos a sua imagem de homem corajoso, ativo e másculo.

No entanto, em 1912 Roosevelt foi derrotado na eleição que lhe daria o seu terceiro mandato na Presidência dos EUA. Deslocado no quadro político nacional, abatido psicologicamente e sem interesse por cargos menores, resolveu fazer uma espécie de retiro 'sabático' naturalista nas florestas tropicais do Brasil, ou seja, planejou viver novas aventuras em 'terras selvagens' tropicais que reforçassem a sua periclitante figura política. Queria cultivar aquela sua imagem de homem de aventuras e assim preparar o seu retorno político (que não ocorreu).

Depois de algumas negociações de alto nível, bem explicadas por Millard, Roosevelt obteve do governo brasileiro autorização para fazer uma expedição pelo interior do Brasil, na companhia de outros norte-americanos. Conseguiu mais ainda: o governo designou o famoso e muito ocupado Rondon - que aceitou sem grande entusiasmo - para ser o comandante de fato e o guia da expedição.

Para o leitor brasileiro, o ponto de maior interesse do livro de Millard é a expedição de Roosevelt e Rondon por Mato Grosso, especialmente a descida do rio da Dúvida, o ponto alto da viagem. Por isso, o restante desta resenha focaliza principalmente essa parte da narrativa, desconsiderando de fora a atenção que a autora dá ao papel de Roosevelt na política interna dos EUA nos últimos anos de sua Presidência e a trechos da viagem de Roosevelt por vários países da América do Sul. O trajeto da expedição em terras brasileiras foi obviamente definido por Rondon, mas dificilmente poderia ter sido mais ao gosto de Roosevelt, que queria passar por aventuras perigosas para ter o que narrar.

A rigor, a viagem de Roosevelt à América do Sul foi bem maior que a expedição pelo Mato Grosso e pelo rio da Dúvida. Ela começou em outubro de 1913, quando el e e pequena comitiva partiram de navio dos EUA, desembarcaram no Rio de Janeiro e viajaram por 
vários trechos do Brasil, Argentina, Chile, Uruguai e Paraguai. A segunda parte começou em dezembro de 1913, em Corumbá, hoje localizado no Mato Grosso do Sul, combinando o uso de barcos pelos rios do Pantanal e a travessia terrestre até Cuiabá e daí até as proximidades do rio da Dúvida, cuja descida (entre fevereiro e abril de 1914) foi o clímax da viagem. Roosevelt ainda chegou a Manaus e de lá partiu para os EUA.

A parte principal e mais difícil da expedição foi essa descida do rio, que hoje se chama Roosevelt. Nela se concentraram as aventuras mais perigosas que o ex-presidente dos EUA viveu. Não estava prevista uma marcha, e sim uma viagem rio abaixo em pequenos barcos. Não foi bem isso o que aconteceu. O rio nasce no que era o noroeste de Mato Grosso (hoje a nascente está em Rondônia, nas proximidades da sede municipal de Vilhena). Saindo de Rondônia, as suas águas atravessam o atual noroeste do Mato Grosso e o sul do Amazonas, num sentido marcadamente Sul-Norte. É um rio de quarta grandeza na bacia amazônica, pois é afluente do rio Aripuanã, que é afluente do Madeira, que é afluente da margem direita do Amazonas. No entanto, ele ainda não fora explorado ou mapeado. O nome indicava o quão pouco era conhecido, inclusive pelo próprio Rondon. As dificuldades de explorar o rio se revelaram de 'primeira grandeza'.

Para reconstruir essa penosa descida fluvial, Millard se vale de um rico conjunto de fontes, digno de uma historiadora profissional - diários, anotações de viagem, cartas, materiais de arquivos pessoais, mapas, fotografias, desenhos e relatórios, além de materiais da Comissão Rondon, do livro do próprio Roosevelt e de publicações de outros participantes. O resultado é uma narrativa vigorosa de uma viagem famosa e que apresenta marcante singularidade no conjunto de viagens de exploração do vasto território amazônico e brasileiro. A singularidade não se deve apenas à participação de um ex-presidente dos EUA, embora esse detal he seja notável, mas principalmente às dificuldades que surpreenderam até os experientes Rondon e equipe.

O obscuro rio da Dúvida mostrou ser muito mais difícil de explorar do que poderiam supor Rondon e Roosevelt. Em vez de uma viagem heroica, mas relativamente segura nas selvas brasileiras, Roosevelt quase morreu. Desde o início, trechos numerosos e longos do rio eram marcados por cachoei ras, corredeiras, estreitos, pedras e quedas d'água. Isso obrigava a estafantes e demoradas operações de descarregar e carregar os barcos, a difíceis manobras dos barcos vazios com a ajuda de cordas e a cansativas caminhadas dos expedicionários pelas margens íngremes e rochosas. O ritmo da viagem caía às vezes a poucas centenas de metros por dia, o que causou grande atraso. Houve acidentes, barcos avariados, equipamentos perdidos, feridos, doentes, fome e mortos. Ocorreu pelo menos um encontro tenso com indígenas (Cintas-largas). Embora nunca avistados, eles mataram a flecha um cachorro da expedição. O próprio Roosevelt ficou gravemente doente (de malária) e feriu seriamente a perna num acidente. $O$ experiente Rondon não previu tantas dificuldades na exploração desse rio, o que sugere que elas não são típicas dos rios dessa parte da bacia amazônica.

Essas dificuldades são fascinantes em si mesmas e estão muito bem narradas, mas induziram a autora a introduzir uma informação duvidosa da qual ela tirou inferências que não cabem numa narrativa tão precisa e documentada. Millard, no prefácio, atribui ao rio da Dúvida uma extensão de "quase 1.000 milhas", ou pouco mais de $1.600 \mathrm{~km}$. 
Consultando três mapas diferentes, no entanto, obtive cifras bem menores - 297, 306 e 341 milhas $(475 \mathrm{~km}, 489 \mathrm{~km}$ e $545 \mathrm{~km}$, respectivamente). A Wikipedia registra $640 \mathrm{~km}$, sem dar a fonte. As discrepâncias entre as quatro últimas cifras podem dever-se ao caráter acentuadamente tortuoso do leito do rio, mas dificilmente isso elevaria a extensão do rio ao patamar da primeira cifra $-1.600 \mathrm{~km}$.

Embora às vezes a autora use cifras menores do que esses $1.600 \mathrm{~km}$, predomina no texto essa estimativa inflada - destacada até na legenda de uma foto. Talvez ela tenha embutido nessa cifra al gumas das centenas de quilômetros que a expedição percorreu desde Corumbá, mas isso não está claro nem seria coerente com a ênfase que a sua narrativa dá à descida do rio. Pode ser também que Millard tenha incluído a distância percorrida depois do rio da Dúvida - da sua confluência com o Aripuanã e Manaus. No entanto, sobre esse trecho da viagem (por rios bem conhecidos - Aripuanã, Madeira e Amazonas) ela não oferece qualquer informação. Para Roosevelt (e os demais), esse trecho foi na verdade um alívio, porque o ex-presidente estava muito enfraquecido e porque os rios e terras estavam dentro das fronteiras do empreendimento comercial da borracha. Embora sofresse os primeiros abalos da concorrência da produção de origem asiática, o empreendimento ainda estava no seu máximo de expansão e abrangência. A aventura do perigoso rio da Dúvida ficara para trás.

A cifra equivocada sobre o comprimento do rio não é em si mesma muito problemática para o texto. O problema maior é que, combinada com as dramáticas e muito bem narradas dificuldades de percurso, ela fez a autora exagerar os feitos da expedição. Como destacado acima, no contexto da bacia amazônica, o rio da Dúvida é apenas modesto. Percorrêlo foi extremamente difícil, mas a sua exploração não "mudou o mapa" da região ou do Mato Grosso, como alega a autora, e obviamente não mudou o mapa da América do Sul (como apregoou Roosevelt). Menos ainda mudou o mapa do "Hemisfério Ocidental" (conforme al ega hiperbolicamente o autor da orel ha da edição original). A expedição RooseveltRondon apenas enriqueceu - sem revolucionar ou mesmo reformar moderadamente - o conhecimento geográfico sobre uma parte da bacia amazônica.

Outro problema derivado do superdimensionamento do rio da Dúvida é que Millard sustenta, em al gumas passagens, que não havia certeza se o rio pertencia à bacia amazônica. Ora, isso não parece ser verdade. Na época suspeitava-se de outra coisa - que o rio tivesse, em suas cabeceiras, uma conexão com a bacia do rio da Prata. No entanto, a expedição Roosevelt-Rondon não teve como missão estudar as cabeceiras desse rio e as suas imaginadas conexões ao Sul com a bacia do Prata, e sim explorar o vale do rio na direção norte, no seu caminho para as terras baixas da Amazônia.

Um fato narrado por Millard desmente a suposta incerteza sobre o pertencimento do rio da Dúvida à bacia amazônica. O próprio Rondon, o melhor conhecedor da região, tinha certeza de que o rio fazia parte da bacia amazônica. Tanto é verdade que ordenou que um destacamento subisse o mais bem conhecido rio Aripuanã, a partir de Manaus, para se encontrar com a expedição Roosevelt-Rondon. Esse encontro aconteceu e foi, aliás, fundamental para salvar a expedição do fracasso e até de uma tragédia.

Outro fato desmente essa suposta incerteza sobre a inserção amazônica do rio da Dúvida. A expedição Roosevelt-Rondon, quando chegou perto do rio Aripuanã, encontrou diversas 
colocações de seringueiros. Isso mostra que o trecho baixo do rio da Dúvida estava integrado ao empreendimento da borracha, o que significa que estava comercialmente 'mapeado' como integrante da dita bacia. Rondon não sabia das enormes dificuldades de explorar o rio, mas sabia muito bem onde ele ia desaguar.

De toda maneira, as dificuldades vividas pelos expedicionários e essas imprecisões da narrativa de Millard têm o mérito de mostrar ao leitor desavisado de hoje como era difícil explorar e mapear a Amazônia há cerca de cem anos, antes dos recursos ligados à aviação, à aerofotogrametria, às imagens de radar do Projeto Radam Brasil, às imagens orbitais e ao GPS.

A Comissão Rondon geralmente agregava cientistas às suas expedições. Alberto José Sampaio (1881-1946) e Frederico Hoehne (1882-1959), por exemplo, dois dos maiores botânicos brasileiros de todos os tempos, participaram de algumas dessas expedições. Sampaio viajou ao Amapá e escreveu sobre a sua flora. Sistematizou dados levantados em outras expedições sobre a flora do Mato Grosso. Hoehne integrou mais de uma expedição de Rondon. Fez observações in loco, coletou enorme quantidade de espécimes, compôs coleções e escreveu numerosos artigos e livros baseados neles.

A expedição ao rio da Dúvida também teve uma dimensão científica, embora não tenha tido uma relevância direta para a ciência praticada no Brasil. Millard registra que o botânico Hoehne fez parte da expedição, a partir de Corumbá. No entanto não desceu o rio da Dúvida, pois se retirou da marcha reclamando da preferência dada por Rondon à participação dos cientistas norte-americanos.

Apenas um cientista acabou descendo o rio da Dúvida, a parte 'nobre' da expedição. Foi ele o norte-americano George Kruck Cherrie (1865-1948), ornitólogo já bem experiente na coleta in loco de espécimes de aves sul-americanas, atividade a que deu continuidade na expedição de 1913-1914. O também norte-americano Leo E. Miller (1887-1952), que desde Corumbá coletou mamíferos, teve de se contentar com uma vaga em um desdobramento da expedição, descendo o já explorado rio Gy-Paraná. Ambos tinham sido indicados a Roosevelt pelo paleontólogo Henry Fairfield Osborn (1857-1935) e pelo ornitólogo Frank Michler Chapman (1864-1945), respectivamente presidente e diretor do American Museum of Natural History, importante instituição científica participante e financiadora de muitas expedições pelo mundo afora. Depois da sua participação na expedição Roosevelt-Rondon, tanto o veterano Cherrie quanto o jovem Miller trabal haram sobre os materiais coletados na expedição e cumpriram prestigiosas carreiras de naturalistas nos EUA.

O livro de Millard é muito bem concebido e resolvido. É recomendado para todos os estudiosos da Amazônia. Interessa também a quem queira conhecer as trajetórias de Rondon e de Roosevelt (nesse caso, especialmente estudiosos da história política norte-americana da virada do século XIX para o XX). Da mesma forma, é uma leitura instigante para estudiosos de expedições e da história da ciência, sendo atraente ainda para um público mais geral que aprecia narrativas de viagens e aventuras. 
José Augusto Drummond

\section{NOTAS}

${ }^{1}$ O livro foi traduzido para o português com o título 0 rio da Dúvida: a sombria viagem de Theodore Roosevelt e Rondon pela Amazônia (São Paulo, Companhia da Letras, 2007; tradução de José Geraldo Couto).

${ }^{2}$ O próprio Roosevelt escreveu um bom livro sobre a expedição: Through the Brazilian wilderness (New York, Da Capo Paperback, 1914), editado em português com o título Nas selvas do Brasil (Belo Horizonte, Itatiaia, 1976; tradução de Luiz Guimarães Junior.

${ }^{3}$ Note-se que o nome de Rondon, que consta do título do livro traduzido para o português, não aparece no titulo do original.

${ }^{4}$ Todd Diacon é outro estudioso estrangeiro que aborda Rondon, nesse caso como personagem principal, com a devida consideração, no livro Stringing together a nation: Cândido Mariano da Silva Rondon and the construction of a modern Brazil, 1906-1930 (Durham, Duke University Press, 2004), editado no Brasil com o título Rondon: perfis brasileiros (São Paulo, Companhia das Letras, 2006). 